\title{
CORRIGENDUM
}

\section{Opposing decadal changes for the North Atlantic meridional overturning circulation}

M. Susan Lozier, Vassil Roussenov, Mark S. C. Reed and Richard G. Williams

Nature Geoscience 3, 728-734 (2010); published online: 12 September 2010; corrected after print: 14 October 2010.

In the version of this Letter originally published, " $-0.8 \pm 0.5 \mathrm{~Sv}$ " in the fifth sentence of the abstract should have read " $+0.8 \pm 0.5 \mathrm{~Sv}$ ". This error has now been corrected in the HTML and PDF versions of the text. 